\title{
OPERA „LUCEAFĂRUL” DE NICOLAE BRETAN
}

Adrian MăRGINEAN*

\begin{abstract}
The opera "The Evening Star" by Nicolae Bretan'. Mihai Eminescu has capitalized in his work the philosophy, the historical rhythm of the age, the science, the wisdom of the ancients, and he also approached universal themes such as "The Time" (considered the leitmotif of his work, the supratema), "Cosmic" - the infinite, cosmic or cosmic crashes, luceps, sky, intergalactic flight, chaos, sphere music; as well as the "condition of the genius creator" Eminescu was a visionary who, in his creations, deeply meditated on the mysteries of the Universe, which he deciphered almost as a scientist. His work has remained an inexhaustible source of inspiration for othercreators. Amongst them was also Nicolae Bretan, composer and conductor, as well as baritone and opera director. He studied at the Conservatory of Cluj. His period of studies was between the years 1906 and 1908. From 1909 he began studying at the Academy of Music in Vienna. In 1912 he began his studies at the Academy of Budapest. Afterwards, he sang as the first baritone of the Bratislava Opera. He received his degree at the Faculty of Philology from Cluj in the year 1916. He was a director at the Hungarian Opera House, in Cluj. He then became director of the Romanian Opera House in Cluj, a fter the opera experienced a period in exile at Timişoara. The opera „The Evening Star” by Nicolae Bretan, on Mihai Eminescu's lyrics, premiered on February 2, 1921 in Cluj, the most recent representation being in 1994, when the "Transilvania" Philharmonic Orchestra in Cluj recorded audio this opera. In recent years, since 2014, the „Nae Leonard” National Opera and Operetta Theater had a series of performances with
\end{abstract}

* University Assistant, Dunărea de Jos University, Faculty of Arts, Galați, Romania; PhD Student, Faculty of Orthodox Teology at „1 Decembrie 1918” University, Alba Iulia, Romania.

${ }^{1}$ Studiu redactat sub îndrumarea Pr. Prof. Dr. Domin Adam, Universitatea „1 Decembrie 1918” din Alba Iulia, care şi-a exprimat acordul pentru publicare. 
this opera in a piano version, and this year, at the commemoration of the 130th anniversary of the death of the poet, the theater's leadership and team wanted to present the whole work in the orchestra version and in a special frame - the garden of the Museum of History, Culture and Christian Spirituality from the Lower Danube - Galati. The directorial idea belongs to the late Maestro Emil Pinghiriac, the staging being given to his disciple, tenor Adrian Mărginean.

Keywords: national poet, tribute, The Evening Star, musical composition, opera.

\section{Introducere}

Mihai Eminescu a valorificat în opera sa ştiinţa, filosofia, ritmul istoric al veacului, înţelepciunea anticilor. Abordează teme universale ca Timpul (considerat laitmotivul operei sale, supratema), cu sentimentul straniu al ireversibilităţii sale; Cosmicul - infinitul, geneze ori prăbuşiri cosmice, luna, soarele, stelele, luceferii, cerul, zborul intergalactic, haosul, muzica sferelor; "Condiţia creatorului de geniu". Eminescu a fost un vizionar care, în creaţiile sale, a meditat profund la tainele Universului pe care le-a descifrat aproape ca un om de ştiinţă. Opera sa a rămas sursă inepuizabilă de inspiraţie pentru alţi creatori.

Printre aceştia se numără şi Nicoale Bretan, compozitor şi dirijor, precum şi bariton, dar şi regizor de operă. A studiat la Conservatorul din Cluj. Perioada de studii a fost între anii 1906 şi 1908. Din 1909 studiază la Academia de Muzică din Viena. În 1912 începe studiul la Academia din Budapesta. Ulterior, a fost prim Bartion al Operei din Bratislava. Licenţa şi-a luat-o la Facultatea de Filologie din Cluj în anul 1916. Regizor la opera maghiară din Cluj. A devenit ulterior director al Operei Române din Cluj, după perioada de surghiun a acesteia în Timişoara.

\section{Caracteristicile creației lui Nicolae Bretan}

Compozitorul Nicolae Bretan (1887-1968) ocupă un loc special în istoria muzicii române. În creaţia sa de operă şi în liedurile sale numeroase, Bretan a căutat natura esenţială a cântecului şi potenţialul expresiv al vocii umane. Personalitatea sa artistică plurivalentă este cea care îi impresionează pe cercetătorii vieţii şi creaţiei sale, şi-i fac să-şi 
dorească să pătrundă mai mult în tainele activităţii sale, căci, pe lângă activitatea de compozitor, Nicolae Bretan a fost dirijor, regizor şi solist de operă.

După data manuscriselor lui Nicolae Bretan şi după indicaţiile personale ale compozitorului, ne dăm seama de procesul îndelungat de creaţie a fiecărei lucrări în parte. Este foarte evident că lucrările din genul operei aveau un ciclu de creaţie mai îndelungat, nu atât din punct de vedere muzical, cât în special din perspectiva ideii şi a substanţei subiectului. PentruBretan, libretul era peun plan secundar, pentru că dacă era necesar, compozitorul transforma textul, pentru a-l potrivi muzicii şi viziunii sale scenice. Creaţiile lui Bretan transmit un mesaj umanitar, fie prin zugrăvirea abisurilor sufletului omenesc, şi aici amintim lucrările: Luceafărul (1921), Golem (1924), Arald (1982), în care se observă ştiinţa creatorului de a expune muzical mizeria şi măreţia naturii umane, fie printr-o umanitate în care iubirea de semeni învinge orice ură şi nedreptate: Eroii de la Rovine (1935) şi Horia (1937).

Din punct de vedere muzical, fiecare operă conţine un limbaj muzical diferit, pe plan melodic dar şi orchestral. Opera Luceafărul debutează cu un Andante religioso, a cărui temă în piano, formată dintrun salt descendent de cvartă perfectă, expus de două ori, cu repetarea sunetului de la bază şi dintr-o melodie sinuoasă cu mers treptat, creează o atmosferă celestă şi, astfel, instaurează ambientul întregii opere:

Ex. nr. 1 -Uvertura operei Luceafărul, măs. $1-8^{2}$

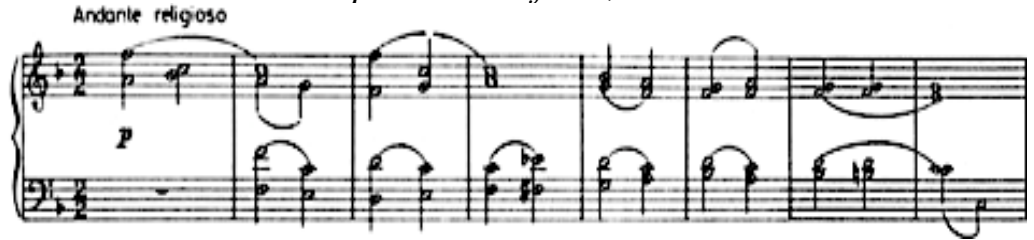

În opera Golem, dimpotrivă, orchestra realizează portretul omului de lut, legat de pământ şi plin de brutalitate, printr-o temă în fortissimo, $\mathrm{cu}$ indicaţia Maestoso, ce izbucneşte la unison din registrul grav, încheindu-se cu o disonanţă - un acord micşorat cu septimă micşorată, rezolvat în Sol major - ce exprimă nedesăvârşirea personajului:

2 Toate exemplele muzicale au fost preluate din partiturile voce-pian ale lucrărilor menționate. 


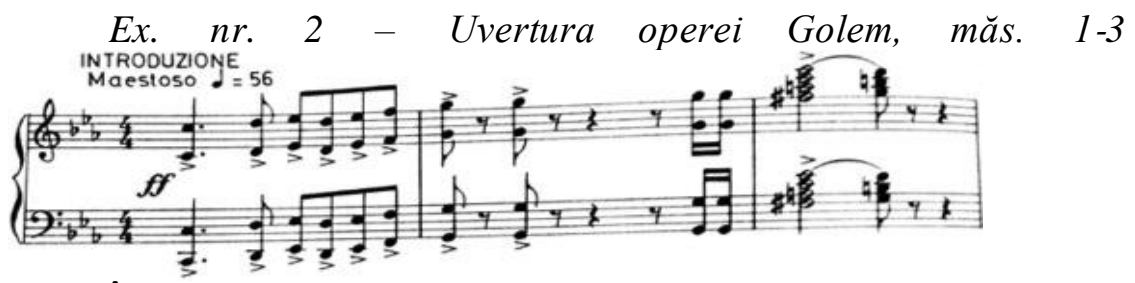

În opera Horia, Bretan împleteşte motive melodice populare care aparţin celor două naţionalităţi aflate mereu în dispută în Transilvania, maghiară şi română, a căror muzică o cunoştea perfect ${ }^{3}$. Deşi faptele istorice prezentate în operă sunt anterioare Revoluţiei Franceze din 1789, compozitorul utilizează un fragment din imnul La Marseillaise ${ }^{4}$, pentru a sugera dorinţa poporului de a se răscula împotriva constrângerilor feudale la care era supus. Alte imnuri prezente în operă sunt Imnul lui Ştefan Arcaşul, care era cunoscut în secolul al XIX-lea:

Ex. nr. 3 - Opera Horia, actul 1, corintroductiv, măs. 1-6

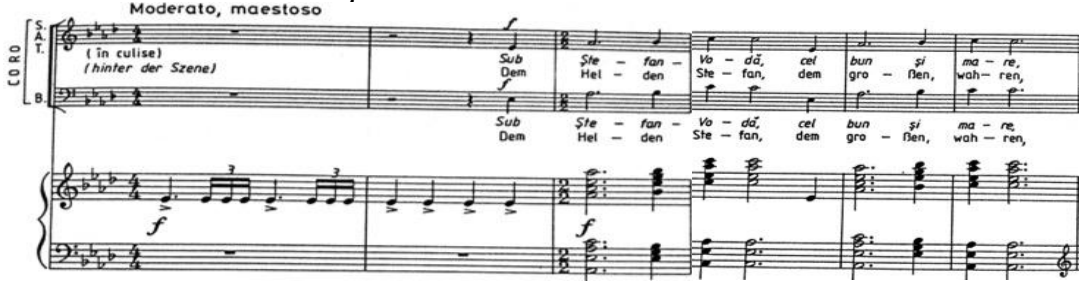

şi, de asemenea, imnul naţional austriac, ce apare în orchestră după ce sentinţa lui Horia este pronunţată, ca o trimitere la hotărârea împăratului austriac. Dar şi viitorul imn naţional al României, Deşteaptăte române, este folosit de compozitor, împreună cu Marşul lui Rákóczi, un cântec maghiar ce are un fundal revoluţionar. Toate aceste motive

${ }^{3}$ Nicolae Bretan, în cartea Viaţa mea, la pagina 11 afirmă: Peste tot ciocnirea dintre aceste două popoare conlocuitoare, exprimată în muzică, am putut-o face eu, care cunosc perfect muzica ambelor naţii.

${ }^{4}$ Pe website-ul: http://www.larousse.fr/encyclopedie/oeuvre/la_Marseillaise/132053 (accesat la data de 02.05.2019) apare următoarea definiţie: La Marseillaise a fost compusă (text iniţial şi muzică) de Rouget de Lisle, la Strasbourg, în noaptea de 25/26 aprilie 1792, după declararea războiului cu Austria. La 30 iulie 1792, melodia a fost cântată de soldaţii republicani din Marsilia la intrarea lor în Paris, de acolo provenind numele La Marseillaise. La 14 iulie 1795, în mod oficial, La Marseillaise a devenit imnul naţional al Franţei. Acest imn a fost orchestrat de Berlioz, apoi, în 1887, de Ambroise Thomas. 
melodice sunt fragmentare şi se întrepătrund de-alungul operei, sugerând astfel istoria zbuciumată a Transilvaniei:

Ex. nr. 4 - Opera Horia, actul 1, corintroductiv, măs. 19-28
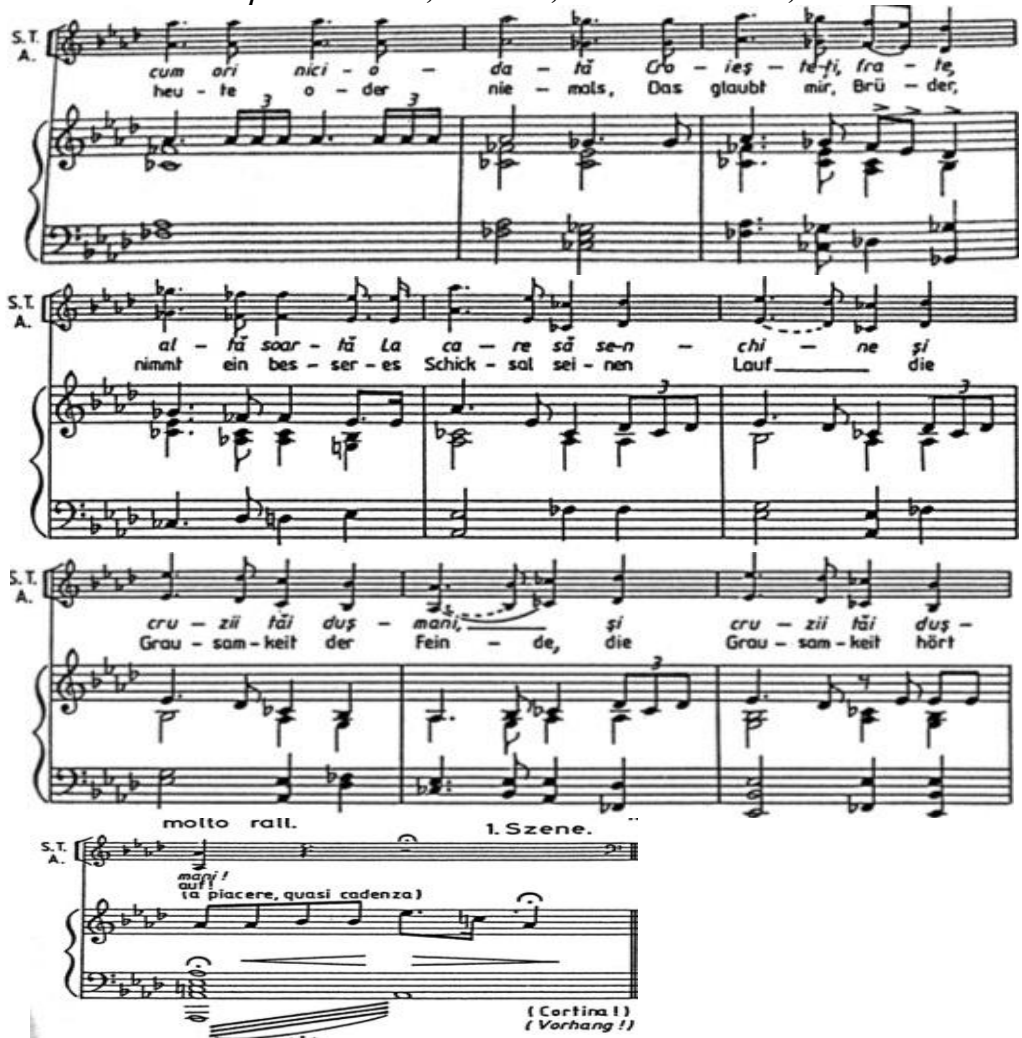

Operelelui Bretan depăşesc tradiţia de operă italiană, iarariile şi duetele sunt construite similar, ocolind bravura, deoarece cântul devine o formă de exprimare a sufletului omenesc, apropiindu-se de originile cântecului.

\section{Opera Luceafărul - viziune regizorală}

Opera într-un act „Luceafărul” a fost definitivată în anul 1921, când a avut premiera la Opera Română din Cluj ${ }^{5}$. Lucrarea a fost scrisă

5 Hartmut Gagelmann, Nicolae Bretan: Liedurile sale, operele lui, viața sa, ClujNapoca, Edit. Teognost, 2005, p. 63. 
pe versurile poetului Mihai Eminescu şi dedicată lui Octavian Goga. Opera conţine melodii complexe, cu salturi mari intervalice, care ilustrează perfect relaţia de iubire şi în acelaşi timp distanţa dintre Fata de Împărat şi astrul care i se arată sub forma unui prinţ blond cu ochi „care o îngheață”, dar şi melodii cu iz folcloric, pentru părţile Pajului, ce sugerează lejeritatea personajului. Bretan a introdus personaje noi faţă de originalul eminescian - Arhanghelul Mihail, Jupâniţa - dama de curte a Fetei de Împărat şi Corăbierul, un personaj episodic, ce potenţează atmosfera misterioasă nocturnă în care se desfăţoară acţiunea. De asemenea, apare şi ansamblul coral, care reprezintă corul stelelor, care intonează imnuri de slavă lui Dumnezeu, dă sfaturi Luceafărului sau comentează acţiunea.

Pentru comemorarea celor 130 de ani de la mutarea la cele veşnice a poetului naţional, Teatrul Naţional de Operă şi Operetă Nae Leonard din Galaţi a repus în scenă opera „Luceafărul”, de data aceasta cu acompaniament orchestral, fapt ce a reprezentat o premieră, deoarece această lucrare nu a mai fost reprezentată cu acompaniament orchestral din anul 1994, când a fost înregistrată pe disc de către Filarmonica din Cluj.

Montarea operei la Galaţi a fost realizată în aer liber, într-un cadru cât se poate de potrivit ocaziei - Grădina Muzeului Episcopal Galați, în colaborare cu Episcopia Dunării de Jos. Date fiind caracteristicile clădirii Muzeului Episcopal, care dispune de un balcon foarte generos deasupra intrării principale, am hotărât ca prin utilizarea acestui balcon să delimitez cele două planuri expuse în operă: astral şi terestru. Pentru că intrarea principalăîn Muzeu este flancată de doi piloni care susţin balconul, a apărut necesitatea amplasării unei scene în faţa intrării. Deoarece elementul de noutateîn acest spectacol-eveniment este prezenţa orchestrei simfonice, am dorit ca prin amplasarea acesteia central, în faţa scenei, să-i ofer grandoare. Această poziţionare a obligat la o înălţare a scenei de 4/8 metri la 1 metru distanţă de pământ, pentru ca relația dintre soliști - cor - auditoriu să se facă fără o interferenţă vizuală din partea orchestrei.

Poziţionarea acestei scene a permis un dialog organic între cele două planuri: terestru - scena la sol; astral - balcon. Rugăciunea adresată de Luceafăr către Divinitate:

"Din haos, Doamne-am apărut

Şi m-aş întoarce-n haos... 
Şi din repaosm-am născut

Mi-e sete de repaos

O, cere-mi, Doamne, orice preț,

Dar dă-mi o altă soartă,

Căci tu izvor ești de vieți

De greul negrei vecinicii,

Părinte, mă dezleagă

Și lăudat pe veci să fii

Pe-a lumii scară-ntreagă"

poate fi exprimată firesc printr-un contact atât emoţional cât şi vizual al astrului ceresc cu plăsmuirea divină. De asemenea, Arhanghelul Mihail, care livrează mesajul Divinităţii către Luceafăr, îşi face apariţia tot în balcon, iar aria lui:

"Hyperion, cei din genuni,

Răsaicu o întreagă lume,

$\mathrm{Nu}$ cere semne și minuni

Care n-au chip şi nume"

permite de asemenea o ,scanare” a întregului spaţiu terestru (scenă şi public), cuvintele: „şi pentru cine vrei să mori, întoarce-te, teindreaptă...", fiind subliniate printr-un contact vizual direct şi cu un puternic efect emoţional.

Pentru a potenţa efectul montării în aer liber, am realizat o proiecţie pe clădirea Muzeului, cu diverse imagini care să sublinieze cele două planuri: Preludiul orchestral ne oferă posibilitatea de completa şi pe faţada clădirii cerul înstelat al nopţii, efectul creat fiind acela de dispariţie a clădirii Muzeului; următoarele momente - prima intervenţie a corului, aria Luceafărului, aria Arhanghelului Mihail şi a doua intervenţie a corului se desfăşoară în acest, ,cer” fără de margini, efectul fiind cel puţin, pe cele două arii, de doi îngeri aflaţi în zbor; momentul solistic al cornului englez din orchestră coincide cu schimbarea unghiului vizual, dintr-unul direcţionat spre cer, într-unul direcţionat spre castelul Fetei de Împărat, aflat la malul mării. Castelul cu metereze îşi face apariţia pe faţada Muzeului, înglobând ferestrele clădirii drept ferestre ale castelului. Pentru ca momentul coborârii Luceafăruluisă nu fie unul sec şi lipsit de continuitate, am hotărât ca licărirea acestui astru ceresc să fie permanent reprezentată pe proiecţie. Această reprezentare vizuală permite un alt 
moment de „dialog” care să sublinieze cele două planuri, de data aceasta între Fata de Împărat şi stea, moment care culminează cu invocarea acestuia:

„Cobori în jos Luceafărblând,

Alunecând pe-o rază,

Pătrunde-n ca să şi în gând

Şi viaţa-miluminează”.

Apariţia Luceafărului din mare este precedată de căderea acestuia din cer, moment subliniat printr-o altă proiecţie video - stea căzătoare. Această proiecţie o vom revedea, dar în sens invers, la momentul reîntoarcerii Luceafărului în cer. După duetul de dragoste dintre Fata de Împărat şi Paj, ne reîntoarcem la imaginea cu cerul infinit din debutul operei: licărirea stelelor prezente pe cerul nopţii fiind întregită de stelele de pe proiecţie. Ne este înfăţişat un Luceafăr înnaripat, cu o aureolă de stea, care îl delimitează de imaginea generală. Ultimele momente ale operei ni-l aduc în prim plan de proiecţie pe Luceafărul poeziei româneşti - poetul Mihai Eminescu.

\section{Concluzii}

O lucrare nemuritoare cum este poezia Luceafărul de Eminescu, are şi un mesaj religios extrem de puternic şi de actual; este şi motivul pentru care două instituţii, una de cultură - Teatrul Naţional de Operă şi Operetă „Nae Leonard” şi alta clericală, cum este Arhiepiscopia Dunării de Jos şi-au dat mâna pentru realizarea acestei maniferstări culturale. Cuvintele aştemute în finalul operei sunt inspirate:

„Era un vis misterios

Şi blând, şi blând din calea-a fară,

Şi prea era de tot frumos

De-a trebuit să piară.

Prea ne pierdurăm tu şi eu

Înal ei farmec poate

Prea am uitat de Dumnezeu,

Precum uitarăm toate"

Ele descriu cu multă exactitate realitatea societăţii actuale. 


\section{Anexe}
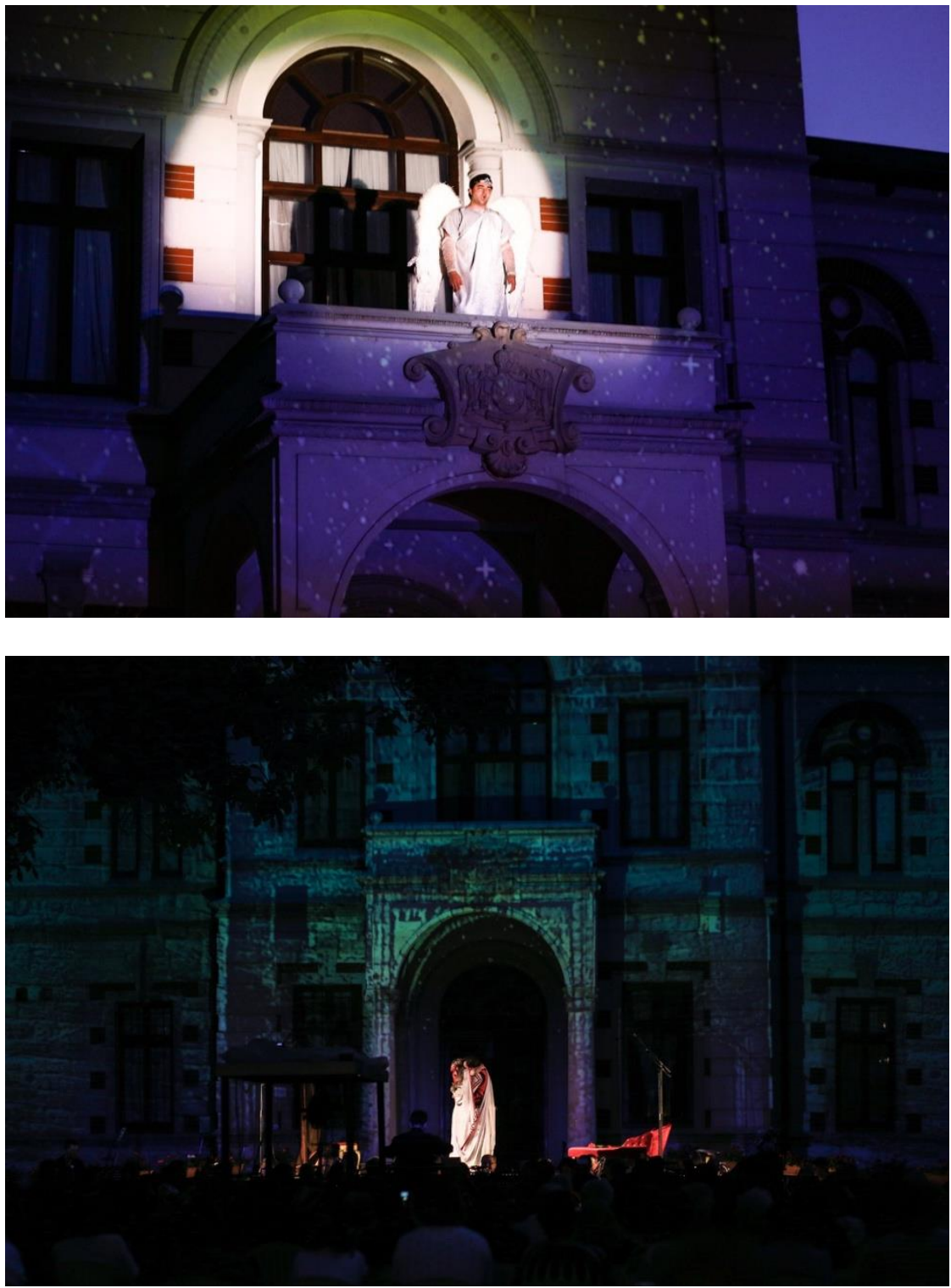

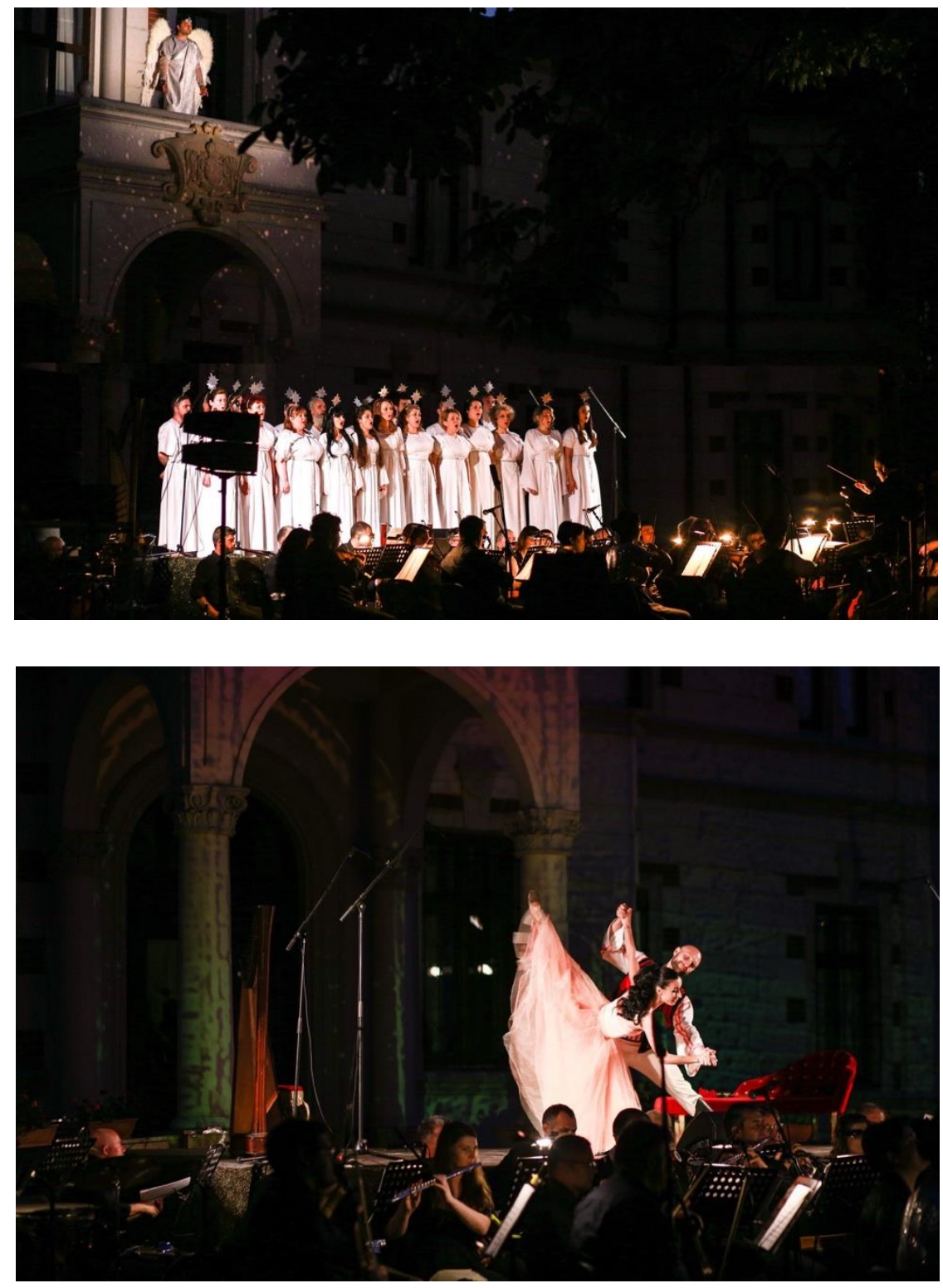


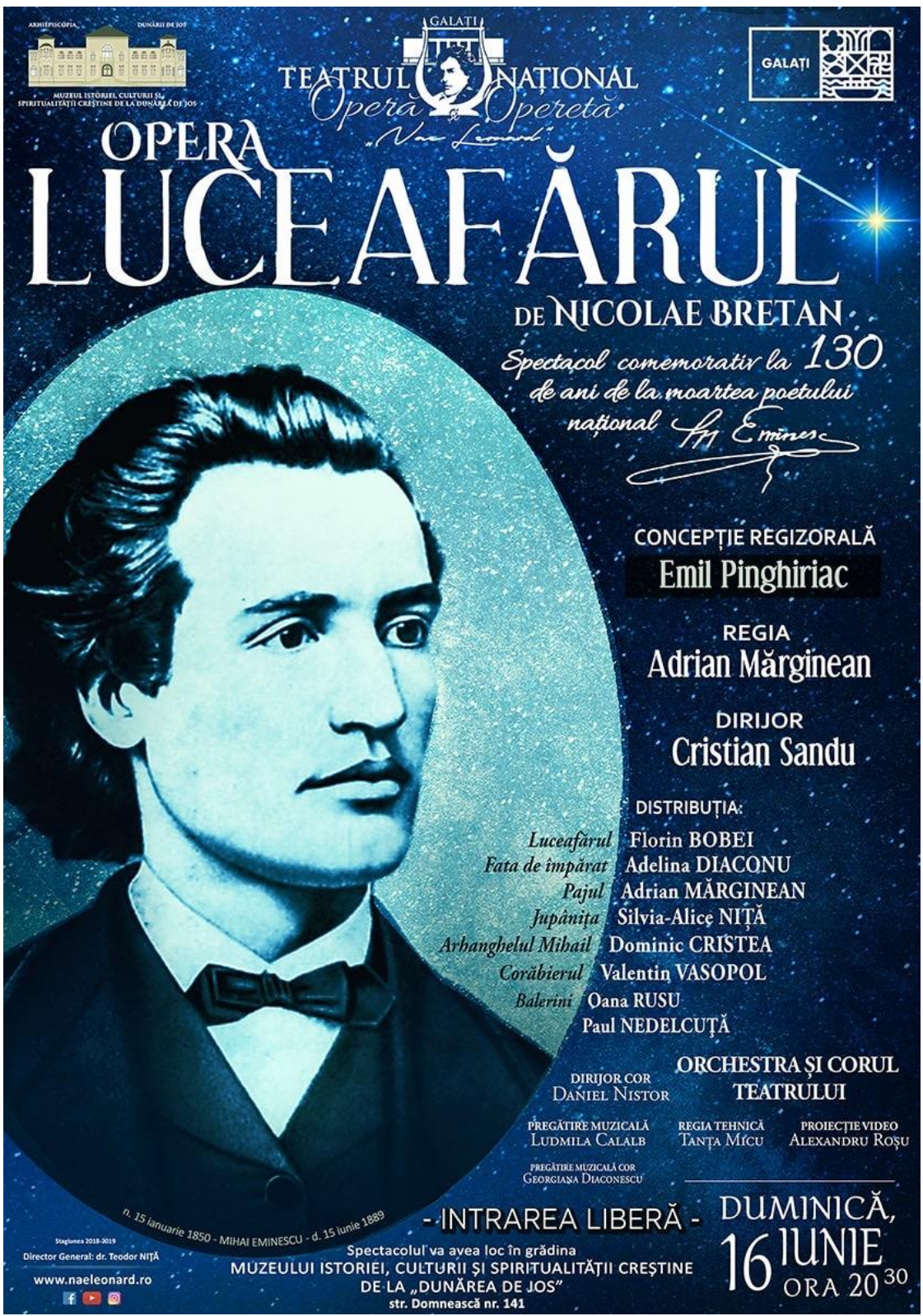




\section{Referinţe bibliografice:}

1. BRETAN, Nicolae, Viața mea, Cluj-Napoca, 1939;

2. BRETAN, Nicolae, opera Luceafărul, partitură voce-pian, s.a.;

3. BRETAN, Nicolae, opera Golem, partitură voce-pian, s.a.;

4. BRETAN, Nicolae, opera Horia, partitură voce-pian, s.a.;

5. GAGELMANN, Hartmut, Nicolae Bretan: Liedurile sale, operele lui, viața sa, Cluj-Napoca, Edit. Teognost, 2005;

6. EMINESCU, Mihai, Luceafărul, București, Edit. Elf, 2013;

7. LAROUSSE: La Marseillaise, disponibil la : http://www.larousse.fr/encyclopedie/oeuvre/la_Marseillaise/132053 (accesat la 02.05.2019);

8. http://www.vopus.org/ro/gnoza-gnosticism/intelepciuneagnostica/poezia-luceafarul-de-mihai-eminescu.html;

9. https://www.facebook.com/Liga-Transilvania-Democrat\%C4\%83679299692143262/posts/;

10. https://bibliotecapemobil.ro/content/scoala/pdf/Poezii\%20 $\% 20$ M.Eminescu.pdf;

11.https://en.wikipedia.org/wiki/Nicolae_Bretan;

12. http://www.lumeacredintei.com/stiri-generale-evenimente/spectacolcomemorativ-la-130-de-ani-de-la-moartea-poetului-national-mihaieminescu/;

13. https://www.antidotul.ro/2019/06/luceafarul-premiera-la-tea trulnational-nae-leonard/. 